\title{
Does low-cost GIC have the same survival rate as high-viscosity GIC in atraumatic restorative treatments? A RCT
}

Marcoeli Silva de MOURA ${ }^{(a)}$

Geovanna Peres de SOUSA(a)

Maria Hellen Sâmia Fortes BRITO(a)

Mikaelle Claro Costa SILVA ${ }^{(a)}$

Marina de Deus Moura de LIMA(a)

Lúcia de Fátima Almeida de Deus MOURA ${ }^{(a)}$

Renata Corrêa PASCOTTO(b)

Cacilda Castelo Branco LIMA(b)

(a) Universidade Federal do Piauí - UFPI, Department of Pathology and Dental Clinics, Teresina, Pl, Brazil.

(b) Universidade Estadual de Maringá - UEM, Center for Biological Sciences, Department of Dentistry, Maringá, PR, Brazil.

Declaration of Interests: The authors certify that they have no commercial or associative interest that represents a conflict of interest in connection with the manuscript.

Corresponding Author:

Marcoeli Silva de Moura

E-mail: marcoeli-moura@uol.com.br

Submitted: August 28, 2019

Accepted for publication: November 4, 2019

Last revision: December 6, 2019
Abstract: Atraumatic Restorative Treatment (ART) is one of the strategies used to control dental caries; it involves hand instruments for removal of carious tissue, and restorations using high-viscosity Glass Ionomer Cement (GIC). The present controlled clinical trial aimed to evaluate the performance of low-cost GIC indicated for ART in primary teeth, compared with high-viscosity GIC, after one year of follow-up. Two-to six-year-old children with dentin caries lesions on one or two surfaces of anterior and posterior teeth were selected. The children were randomly assigned to 2 groups according to the restorative material used: G1 (control) - Ketac Molar ${ }^{\circledR}$; G2 (experimental) - Vitro Molar ${ }^{\circledR}$. Treatments were performed in a school setting, following the guidelines of the ART. A total of 728 restorations were performed in 243 children. Descriptive analysis and Poisson regression were applied, with a significance level of $\mathrm{p}<0.05$. After 12 months, 559 (76.8\%) restorations were re-evaluated. The success rate was evaluated by the prevalence ratio (PR), associated with restorations performed in primary second molars $(\mathrm{PR}=1.21 ; 95 \% \mathrm{CI}=1.03-1.42)$, and with small $(\mathrm{PR}=1.35$; $95 \% \mathrm{CI}=1.14-1.60)$ or medium cavities $(\mathrm{PR}=1.29 ; 95 \% \mathrm{CI}=1.08-1.55)$, using Ketac Molar ${ }^{\circledR}$ material $(\mathrm{PR}=1.07 ; 95 \% \mathrm{CI}=1.01-1.15)$, considering $\mathrm{p}<0.05$. Small or medium restorations in primary second molars performed with high-viscosity GIC (Ketac Molar $\left.{ }^{\circledR}\right)$ were more successful than restorations performed with low-cost GIC indicated for ART.

Keywords: Dental Atraumatic Restorative Treatment; Glass Ionomer Cements; Tooth, Deciduous; Dental Caries.

\section{Introduction}

Dental caries is the most prevalent disease in the oral cavity. A trend toward decline in caries in the permanent dentition has been recorded due to the use of fluorides. ${ }^{1}$ However, it is still the most common chronic disease in children. ${ }^{2,3}$ Unmanaged dental caries is one of the ten most prevalent health problems during childhood, affecting $9 \%$ of the world population, ${ }^{4}$ and caries is the fourth most expensive chronic disease to treat. $^{5}$ In Brazil, $53 \%$ of five-year-old children have dental caries. ${ }^{6}$ 
The treatment of caries lesions involves the approach of health promotion, disease control, and rehabilitation of damages. ${ }^{7}$ Atraumatic Restorative Treatment (ART) is a minimally invasive and low-cost alternative, widely used in communities with difficult access to dental services, and in locations lacking technological resources and/or electricity. ${ }^{8,9}$ This technique consists of removing carious tissue using hand instruments. ${ }^{10}$ The restoration is performed with high-viscosity Glass Ionomer Cement (GIC), a material that adheres chemically to the dental surface, releases fluoride, and is biocompatible. ${ }^{11,12}$ Because the technique is efficient and long-lasting, ${ }^{10,13}$ its use has been extended to treat children and patients displaying anxiety. ${ }^{14}$

High-viscosity GIC was developed for this technique, because it has good mechanical properties, and can easily be inserted into the cavities using digital pressure. ${ }^{10}$ The brands available are very costly to Brazil's public health systems. In the Brazilian market, there are low-cost products sold and certified for ART by the manufacturers, and their packaging reads "indicated for ART." 15,16 However, there is no consensus regarding the most suitable restorative material for use in primary teeth, ${ }^{17,18,19,20}$ and few controlled clinical trials have been performed by dentists. ${ }^{21}$ Therefore, the objective of this study was to evaluate the clinical performance of a low-cost GIC indicated for ART in primary teeth, compared with that of a high-viscosity GIC.

\section{Methodology}

\section{Trial design}

The present protocol was written following the guidelines of CONSORT (Consolidated Standards of Reporting Trials). It was a randomized controlled trial registered at REBEC (RBR-4NWMK4). This research was approved by the local research ethics committee (number: 708.718).

\section{Sample size and selection}

The sample size was based on a $65 \%$ survival rate of the restorations ${ }^{22}$, using the equation $n=z^{2} . p .(1-p) /$ $\mathrm{e}^{2}$, in which $\mathrm{z}$ is the quantile of normal distribution (for a $95 \% \mathrm{CI}, \mathrm{z}=1.96$ ), $\mathrm{p}$ is the estimated variation
$(65 \%)$, and e is the margin of error considered (5\%). A minimum sample of 349 restorations with each material was obtained to develop the study.

\section{Eligibility criteria}

Only the children whose parents signed a free and informed consent form, sent in the child's backpack, were included. Children aged two-to-six years, enrolled in public daycare centers, with primary single- or multiple-surface dentin caries lesions in vital anterior and posterior primary teeth were included. Children who presented teeth with painful symptomatology or signs of pulp involvement, such as fistulas or exposed pulp chamber, were excluded. Uncollaborative children were excluded from the survey.

\section{Blinding (masking)}

Two treatment groups were formed: Group 1 (G1) - control, in which the primary molars were restored with a high-viscosity GIC, and Group 2 (G2) experimental, in which a low-cost GIC for ART was used as the restorative material. This study was double-blind; that is, the patients and the dental surgeon who evaluated the restorations were not aware of the restorative material used.

Opaque envelopes containing the name of the material to be used enabled randomization and ensured concealment of the respective allocations. The material to be used was selected consecutively for each tooth inserted in the study, so that each child would have one or both materials used in his mouth. The envelope was opened by the auxiliary, who delivered the material that was readied for use by the operators, after cavity preparation. The cavities were of different types (Class I, II or II / V) and sizes (small - compromising up to $1 / 3$ of the surface), medium - from $1 / 3$ to $2 / 3$ of the surface, and large - more than $2 / 3$ of the surface). At the end of the study, the high-viscosity and low-cost GIC groups were matched for cavity type and size.

\section{Interventions}

Supervised dental brushing was performed prior to the examinations. A clinical examination was performed to determine the $\mathrm{dmft}$ index (total 
number of decayed, missing and filled teeth). ${ }^{1}$ The restorations were performed in daycare centers, in a room reserved for the study, with the child sitting in a chair, with his head resting on the legs of the dentist. Artificial lighting from a portable lamp was used (Pelican-Startec, 127V).

The clinical approach followed the ART guidelines proposed by Frencken and Holmgren. ${ }^{8}$ When needed, the cavities were accessed using an "opener," a manual cutting instrument used to break unsupported enamel prisms (Kit ART SS White, Rio de Janeiro, Brazil), and the carious tissue was removed (selective removal of infected and disorganized dentin), using hand instruments (Kit ART SS White, Rio de Janeiro, Brazil). The cavities were then conditioned for 10 seconds with cotton balls embedded in polyacrylic acid (DFL, Rio de Janeiro, Brazil), washed for five seconds with watersoaked cotton balls, and then dried with cotton balls. The cavities were randomized and assigned to the test materials. In Group 1, the cavities were restored with Ketac Molar ${ }^{\circledR}$ high-viscosity GIC (3M / ESPE, Seefeld, Germany), and in Group 2, they were restored with the GIC indicated for ART by the Vitro Molar ${ }^{\circledR}$ manufacturer (DFL, Rio de Janeiro, Brazil). Both GIC varieties were handled on a glass plate with a metal spatula (Duflex / SS White, Rio de Janeiro, Brazil) according to the manufacturer's specifications.

The GIC was inserted into the cavity using an insertion instrument (Kit ART SS White, Rio de Janeiro, Brazil) and pressed into the cavity with a gloved finger coated with solid petroleum jelly (Rioquímica ${ }^{\circledast}$, São Paulo, Brazil). ${ }^{23}$ The occlusion was checked using carbon paper (Angelus ${ }^{\circledR}$, Londrina, Brazil), and the excess material was removed using a carver. In proximal cavities, wood wedges (TDV ${ }^{\circledR}$, Santa Catarina, Brazil) and a steel matrix $\left(\mathrm{TDV}^{\circledR}\right.$, Santa Catarina, Brazil) were used. Restorations were performed using cotton rolls for relative isolation. The time to prepare and restore the cavity was measured using a digital timer (Prodigital, Curitiba, Brazil). Restorations were performed by two trained and calibrated dental surgeons (MSM and MHSFB). There was no difference between the operators regarding the survival of the restorations ( $p=0.98$ ).

\section{Evaluation}

A dental surgeon, who was an expert in clinical studies on primary teeth, and blind to the GIC type, evaluated the restorations according to the ART evaluation criteria, after 6 and 12 months. ${ }^{24}$ The restorations were classified according to scores ranging from 0 to 9 , as follows: $0=$ present, satisfactory; 1 = present, with defects smaller than $0.5 \mathrm{~mm} ; 2=$ present and extending into the proximal margins by $0.5 \mathrm{~mm}$ or more; $3=$ present and fractured; $4=$ present and fractured in the tooth; $5=$ present and overextended into the margin by $0.5 \mathrm{~mm}$ or more; 6 = completely or almost completely absent; 7 = not present, and another treatment was performed; $8=$ missing tooth; and $9=$ unable to diagnose. Measurements in millimeters were made using the spherical tip of the $0.5 \mathrm{~mm}$ WHO probe. The exams were carried out at the daycare centers under same conditions as those for performing the restorations, using a flat mouth mirror (Duflex, SS White, Rio de Janeiro, Brazil), WHO probe (Millennium, Golgran, São Caetano do Sul, Brazil), and compressed air syringe from a portable compressor (Schulz ${ }^{\circledR}$, MS 2.3 Air Plus Bivolt, Joinville, Brazil). Restorations coded 0 and 1 were considered successful; those coded from 2 to 6 were considered failures; and codes from 7 to 9 were disregarded from the evaluation. ${ }^{23}$ A dentin caries cavity, along with the restoration (secondary caries), was considered a failure. All evaluations were performed by an independent evaluator, trained and calibrated by a specialist $($ Kappa $=0.87)$.

\section{Statistical methods}

The Statistical Package for the Social Sciences (SPSS ${ }^{\circledR}$ for Windows, 20.0 version, Armonk, NY, USA: IBM Corp) was used to conduct the statistical analysis. Initially, absolute and relative frequencies of the variables were described. The dependent variables, namely survival of the restorations to 6 and 12 months, were dichotomized as success or failure. The independent variables were tooth, cavity type and size, and material. Poisson regression was performed with robust variance. The variables with a value of $p \leq 0.20$ in the bivariate analysis were included in the multivariate analysis. The results 
were expressed as a prevalence ratio (PR), with a 95\% confidence interval $(95 \% \mathrm{CI})$, and associations with $\mathrm{p}<0.05$ were retained in the final model.

\section{Results}

A total of 1,077 preschoolers participated in this study; the majority were four-year-olds (410, 38.1\%) (Table 1). A total of 21,540 teeth were evaluated, $728(3.4 \%)$ of which required treatment and were indicated for ART. At the end of the 12 months, there was a loss of 169 teeth, corresponding to a response rate of $76.8 \%$. There was a $41.4 \%$ prevalence of caries, and the mean $\mathrm{dmft}$ was higher in the six-year-old group (2.37 \pm 2.8$)$ (Table 1). In all, 728 restorations were performed $(\mathrm{G} 1=341$ and $\mathrm{G} 2=387)$ in 243 children . Figure presents the flowchart of the study.

After 6 months, 565 (77.6\%) restorations were re-evaluated. Of the losses, two $(0.27 \%)$ were from missing teeth, 106 (14.5\%) were from children who had left the daycare center, and 55 (7.5\%) were from children who were absent on the days of the three attempted re-evaluations. In this period, the success of the restorations was associated with female preschoolers $(\mathrm{PR}=1.07,95 \% \mathrm{CI}=1.00-1.14)$, primary second molars $(\mathrm{PR}=1.15,95 \% \mathrm{CI}=1.02-1.31)$, teeth with small $(\mathrm{PR}=1.23,95 \% \mathrm{CI}=1.07-1.40)$ and medium cavities $(\mathrm{PR}=1.17,95 \% \mathrm{CI}=1.02-1.35)$ ), and those restored with Ketac Molar ${ }^{\circledR}(\mathrm{PR}=1.07$, $95 \% \mathrm{CI}=1.01-1.15)$ (Table 2).

After twelve months, 559 (76.8\%) restorations were re-evaluated. Of the losses, two $(0.27 \%)$ were from missing teeth, 112 (15.4\%) were from children who had left the daycare center, and 55 (7.5\%) were from those who were absent on the days of the three attempted re-evaluations. In the final model for this period, the success of the restorations was associated with second molars (PR $=1.21 ; 95 \% \mathrm{CI}=1.03-1.42)$, teeth with small $(\mathrm{PR}=1.35 ; 95 \% \mathrm{CI}=1.14-1.60)$ and medium cavities $(\mathrm{PR}=1.29 ; 95 \% \mathrm{CI}=1.08-1.55)$, and restorations with Ketac Molar ${ }^{\circledR}(\mathrm{PR}=1.07$; $95 \% \mathrm{CI}=1.01-1.15)$ (Table 3).

\section{Discussion}

ART recommends use of high-viscosity GIC, developed especially for this technique. In this study, better clinical performance by the highviscosity GIC was observed after 12 months of monitoring, compared with the conventional GIC indicated for ART. High-viscosity GICs have a higher powder-liquid ratio (>3.6:1), smaller particles

Table 1. Prevalence and severity of dental caries measured by mean $\mathrm{dmft} / \mathrm{dmfs}$ by age

\begin{tabular}{|c|c|c|c|c|c|c|c|c|c|c|c|c|c|c|}
\hline \multirow{2}{*}{$\begin{array}{l}\text { Age } \\
\text { (years) }\end{array}$} & \multirow{2}{*}{ n (\%) } & \multirow{2}{*}{$\begin{array}{c}\mathrm{dmft}=0 \\
\mathrm{n} \\
\%)\end{array}$} & \multirow{2}{*}{ 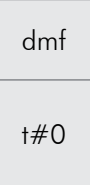 } & \multirow{2}{*}{$\begin{array}{c}\begin{array}{c}\text { mean } \\
\mathrm{dmft}\end{array} \\
( \pm \mathrm{SD})\end{array}$} & \multirow{2}{*}{$\begin{array}{c}\mathrm{dmft} \text { median } \\
\text { (minimum- } \\
\text { maximum) }\end{array}$} & \multicolumn{3}{|c|}{ Component } & \multirow{2}{*}{$\begin{array}{l}\text { mean } \\
\mathrm{dmfs} \\
( \pm \mathrm{SD})\end{array}$} & \multicolumn{5}{|c|}{ Surface involved } \\
\hline & & & & & & $d$ & $\mathrm{~m}$ & $f$ & & $b$ & I & $\mathrm{m}$ & $d$ & ० \\
\hline \multirow{2}{*}{2} & 37 & 30 & 7 & 1.00 & 0.0 & 1.00 & \multirow{2}{*}{ - } & & 1.59 & 0.27 & 0.08 & 0.41 & 0.32 & 0.65 \\
\hline & (3.4) & $(81.1)$ & (18.9) & (2.7) & $(0-14)$ & $(2.7)$ & & & (4.5) & $(0.9)$ & $(0.2)$ & (1.5) & $(0.8)$ & $(1.4)$ \\
\hline \multirow{2}{*}{3} & 267 & 178 & 89 & 1.25 & 0.0 & 1.16 & & 0.09 & 1.59 & 0.16 & 0.14 & 0.31 & 0.22 & 0.83 \\
\hline & $(24.8)$ & (66.7) & (33.3) & (2.3) & $(0-12)$ & $(2.2)$ & & $(0.6)$ & (3.4) & $(0.7)$ & $(0.5)$ & $(0.9)$ & $(0.7)$ & $(1.7)$ \\
\hline \multirow{2}{*}{4} & 410 & 236 & 174 & 1.68 & 0.0 & 1.16 & 0.01 & 0.08 & 2.49 & 0.23 & 0.24 & 0.48 & 0.47 & 1.08 \\
\hline & $(38.1)$ & $(58.0)$ & $(42.0)$ & (2.7) & $(0-16)$ & $(2.2)$ & $(0.1)$ & $(0.4)$ & $(4.6)$ & $(0.7)$ & $(0.7)$ & (1.2) & $(1.1)$ & (1.8) \\
\hline \multirow{2}{*}{5} & 306 & 162 & 144 & 2.04 & 0.0 & 1.6 & 0.02 & 0.26 & 3.14 & 0.27 & 0.29 & 0.61 & 0.67 & 1.32 \\
\hline & $(28.4)$ & $(52.9)$ & $(47.1)$ & (3.2) & $(0-17)$ & (2.7) & $(0.1)$ & $(0.9)$ & (5.7) & $(0.8)$ & (0.9) & (1.6) & (1.5) & $(2.0)$ \\
\hline \multirow{2}{*}{6} & 57 & 23 & 34 & 2.37 & 1.0 & 1.75 & & 0.19 & 3.7 & 0.32 & 0.25 & 0.79 & 0.88 & 1.47 \\
\hline & (5.3) & $(40.4)$ & $(59.6)$ & (2.8) & $(0-10)$ & (3.0) & & $(0.7)$ & (5.1) & (0.9) & $(0.8)$ & (1.6) & (1.3) & $(2.0)$ \\
\hline \multirow{2}{*}{ Total } & 1.077 & 631 & 446 & & & & & & & & & & & \\
\hline & (100.0) & $(58.6)$ & $(41.4)$ & & & & & & & & & & & \\
\hline
\end{tabular}




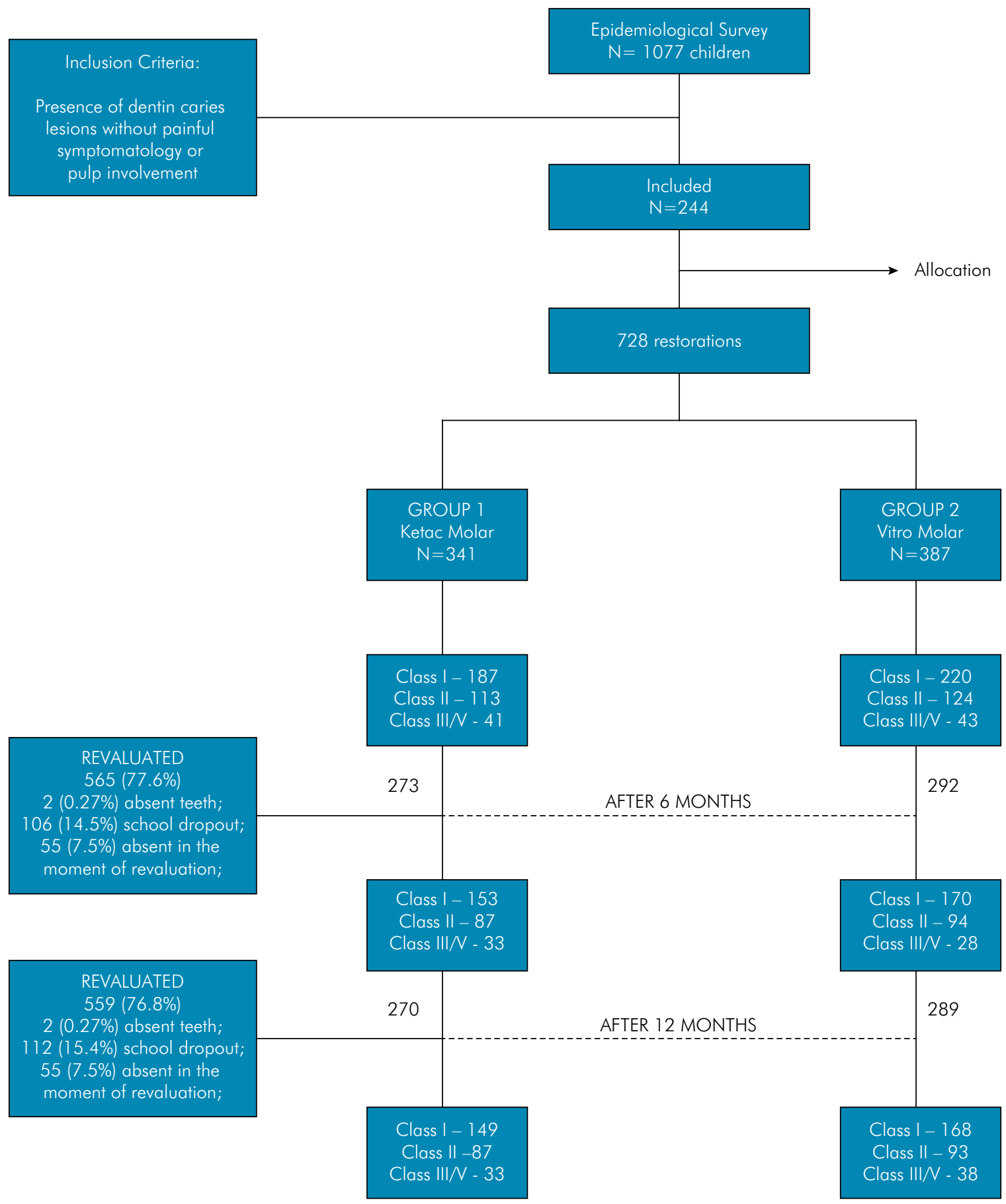

Figure. Flowchart of the study.

( $2 \mu \mathrm{m})$, and 7 to $9 \%$ of lyophilized acid aggregated to the powder. In the Brazilian market, there are low-cost GIC brands indicated for ART, which have not been tested adequately in clinical studies. ${ }^{25}$ The fact that ART is indicated on the package makes the dental surgeon believe that it is a high-viscosity GIC. It is relevant to study these materials because high-viscosity GICs cost more, thus limiting their use in low-income populations and in the public health system. 
Does low-cost GIC have the same survival rate as high-viscosity GIC in atraumatic restorative treatments? A RCT

Table 2. Factors associated with the survival of restorations after six months.

\begin{tabular}{|c|c|c|c|c|c|c|}
\hline \multirow{2}{*}{ Variable } & \multirow{2}{*}{ Success n(\%) } & \multirow{2}{*}{ Failure $\mathrm{n}(\%)$} & Non adjusted PR & \multirow{2}{*}{ p-value } & Adjusted PR & \multirow{2}{*}{$\mathrm{p}$-value } \\
\hline & & & $95 \% \mathrm{Cl}$ & & $95 \% \mathrm{Cl}$ & \\
\hline \multicolumn{7}{|l|}{ Sex } \\
\hline Female & $238(87.8)$ & $33(12.2)$ & $1.07(0.99-1.14)$ & 0.066 & $1.07(1.00-1.14)$ & 0.05 \\
\hline Male & 242 (82.3) & $52(17.7)$ & 1 & & 1 & \\
\hline \multicolumn{7}{|l|}{ dmft } \\
\hline 0-2 (low) & $76(84.4)$ & $14(15.6)$ & $0.99(0.90-1.10)$ & 0.968 & & \\
\hline 3 (average) & $63(87.5)$ & $9(12.5)$ & $1.03(0.94-1.14)$ & 0.497 & & \\
\hline$>3$ (high) & $341(84.6)$ & $62(15.4)$ & 1 & & & \\
\hline \multicolumn{7}{|l|}{ Arch } \\
\hline Lower & 275 (85.9) & $45(14.1)$ & $1.03(0.96-1.10)$ & 0.460 & & \\
\hline Upper & $205(83.7)$ & $40(16.3)$ & 1 & & & \\
\hline \multicolumn{7}{|l|}{ Side } \\
\hline Right & $234(85.4)$ & $40(14.6)$ & $1.01(0.94-1.08)$ & 0.774 & & \\
\hline Left & $246(84.5)$ & $45(15.5)$ & 1 & & & \\
\hline \multicolumn{7}{|l|}{ Tooth $^{a}$} \\
\hline First molar & $189(83.3)$ & $38(16.7)$ & $1.10(0.96-1.26)$ & 0.189 & $1.10(0.96-1.25)$ & 0.157 \\
\hline Second molar ${ }^{b}$ & $231(89.2)$ & $28(10.8)$ & $1.17(1.03-1.34)$ & 0.016 & $1.15(1.02-1.31)$ & 0.023 \\
\hline Anterior & $60(75.9)$ & $19(24.1)$ & 1 & & 1 & \\
\hline \multicolumn{7}{|l|}{ Materiala $^{a}$} \\
\hline Ketac Molar & $240(87.9)$ & $33(12.1)$ & $1.07(0.99-1.15)$ & 0.057 & $1.07(1.01-1.15)$ & 0.045 \\
\hline Vitro Molar & $240(82.2)$ & $52(17.8)$ & 1 & & 1 & \\
\hline \multicolumn{7}{|l|}{ Cavity type $^{a}$} \\
\hline Class I & $293(90.7)$ & $30(9.3)$ & $1.15(1.01-1.32)$ & 0.039 & - & - \\
\hline Class II & $139(76.8)$ & $42(23.2)$ & $0.98(0.84-1.14)$ & 0.755 & - & - \\
\hline Class III/N & $48(78.7)$ & $13(21.3)$ & 1 & & - & - \\
\hline \multicolumn{7}{|l|}{ Cavity size $^{a}$} \\
\hline Smallb & $284(89.0)$ & $35(11.0)$ & $1.26(1.10-1.44)$ & 0.001 & $1.23(1.07-1.40)$ & 0.002 \\
\hline Medium $^{b}$ & $128(85.3)$ & $22(14.7)$ & $1.20(1.04-1.39)$ & 0.012 & $1.17(1.02-1.35)$ & 0.029 \\
\hline Large & $68(70.8)$ & $28(29.2)$ & 1 & & 1 & \\
\hline \multicolumn{7}{|l|}{ Duration (minutes) } \\
\hline$\geq 6$ & $238(86.5)$ & $37(13.5)$ & $1.04(0.97-1.11)$ & 0.303 & & \\
\hline$\leq 5$ & $242(83.4)$ & $48(16.6)$ & 1 & & & \\
\hline Total & $480(85.0)$ & $85(15.0)$ & & & & \\
\hline
\end{tabular}

The values between parentheses refer to percentages in columns. PR: Prevalence ratio; $95 \% \mathrm{Cl}$ : $95 \%$ confidence interval. ${ }^{\circ}$ Variables incorporated into the multivariate model $(p<0.20)$ : sex, material, tooth, cavity type, and cavity size; bariables with $p<0.05$ in the final model.

The first clinical trials evaluating low-cost GIC were published in 2017.15,21 In this study, a difference between the two cements (Ketac Molar ${ }^{\circledR}$ and Vitro Molar $\left.{ }^{\circledR}\right)$ was observed when evaluated after six and twelve months, in that the high-viscosity GIC showed the best performance. Olegário et al..$^{15}$ evaluated a high-viscosity GIC (Gold Label 9 - GC Corp, St. Paul, USA) and found a higher success rate than the low-cost GIC (Maxxion R FGM, Joinville, Brazil and Vitro Molar ${ }^{\circledR}$ DFL, Rio de Janeiro, Brazil). However, 
Table 3. Factors associated with the survival of restorations after twelve months.

\begin{tabular}{|c|c|c|c|c|c|c|}
\hline \multirow{2}{*}{ Variable } & Success & Failure & Non adjusted PR & \multirow{2}{*}{$p$-value } & Adjusted PR & \multirow{2}{*}{ p-value } \\
\hline & $n(\%)$ & $n(\%)$ & $95 \% \mathrm{Cl}$ & & $95 \% \mathrm{Cl}$ & \\
\hline \multicolumn{7}{|l|}{ Sex } \\
\hline Female & $209(78.0)$ & 59 (22.0) & $1.00(0.92-1.10)$ & 0.85 & & \\
\hline Male & $225(77.3)$ & $66(22.7)$ & 1 & & & \\
\hline \multicolumn{7}{|l|}{$\mathrm{dmft}$} \\
\hline 0-2 (low) & $72(79.1)$ & 19 (20.9) & $1.02(0.90-1.15)$ & 0.731 & & \\
\hline 3 (average) & $52(76.5)$ & $16(23.5)$ & $0.98(0.85-1.13)$ & 0.854 & & \\
\hline$>3$ (high) & $310(77.5)$ & $90(22.5)$ & 1 & & & \\
\hline \multicolumn{7}{|l|}{ Arch } \\
\hline Upper & $189(77.1)$ & 56 (22.9) & $1.01(0.92-1.10)$ & 0.804 & & \\
\hline Lower & $245(78.0)$ & 69 (22.0) & 1 & & & \\
\hline \multicolumn{7}{|l|}{ Side } \\
\hline Right & $214(78.4)$ & 59 (21.6) & 1.01 (0.93-1.12) & 0.678 & & \\
\hline Left & & $66(23.1)$ & 1 & & & \\
\hline \multicolumn{7}{|l|}{ Tooth $^{a}$} \\
\hline First molar & $172(76.4)$ & $53(23.6)$ & $1.16(0.97-1.38)$ & 0.093 & $1.15(0.98-1.36)$ & 0.082 \\
\hline Second molar & $210(82.4)$ & 45 (17.6) & 1.25 (1.05-150) & 0.009 & 1.21 (1.03-1.42) & 0.015 \\
\hline Anterior & $52(65.8)$ & 27 (34.2) & 1 & & 1 & \\
\hline \multicolumn{7}{|l|}{ Material $^{a}$} \\
\hline Ketac molar ${ }^{b}$ & $221(82.2)$ & 48 (17.8) & $1.12(1.02-1.22)$ & 0.013 & $1.12(1.02-1.22)$ & 0.011 \\
\hline Vitro molar & $213(73.4)$ & 77 (26.6) & 1 & & 1 & \\
\hline Cavity type $^{a}$ & $49(15.5)$ & & & & & \\
\hline Class I & $268(84.5)$ & & 1.17 (0.99-1.37) & 0.056 & - & - \\
\hline Class II & $122(67.4)$ & 59 (32.6) & $0.93(0.78-1.12)$ & 0.475 & - & - \\
\hline Class III/N & $44(72.1)$ & 17 (27.9) & 1 & & - & - \\
\hline \multicolumn{7}{|l|}{ Cavity size $^{a}$} \\
\hline Small ${ }^{b}$ & $259(82.7)$ & 54 (17.3) & $1.40(1.17-1.65)$ & $<0.001$ & $1.35(1.14-1.60)$ & 0.001 \\
\hline Medium $^{b}$ & $118(78.7)$ & $32(21.3)$ & $1.32(1.10-1.59)$ & 0.003 & $1.29(1.08-1.55)$ & 0.005 \\
\hline Large & $57(59.4)$ & $39(40.6)$ & 1 & & 1 & \\
\hline \multicolumn{7}{|l|}{ Duration (minutes) } \\
\hline$\leq 5$ & $216(76.1)$ & 68 (23.9) & $1.04(0.95-1.13)$ & 0.361 & & \\
\hline$\geq 6$ & $218(79.3)$ & $57(20.7)$ & 1 & & & \\
\hline Total & $434(77.6)$ & $125(22.4)$ & & & & \\
\hline
\end{tabular}

The values between parentheses refer to percentages in columns. PR: Prevalence Ratio. 95\% Cl: 95\% Confidence Interval. " Variables incorporated into the multivariate model $(p<0.20)$ : sex, material, tooth, cavity type, and cavity size. ${ }^{b}$ Variables with $p<0.05$ in the final model.

the study by Pacheco et al..$^{21}$ showed that there was no significant difference in the survival rate between high-viscosity GIC (Ketac Molar $\left.{ }^{\circledR}\right)$ and low-cost GIC (Vitro Molar ${ }^{\circledR}$ ) after 12 months. The results of the latter study contrast with those observed in the present study, probably because only small- to medium-sized proximal occlusal cavities were included in their study, and because the size of our sample was larger.

The main failure was partial or total loss of the restoration. After 12 months, failure rates of $17.8 \%$ 
and $26.6 \%$ were observed for Ketac Molar ${ }^{\circledR}$ and Vitro Molar ${ }^{\circledR}$, respectively. GIC restoration defects can be attributed to incorrect conditioning of the cavity with polyacrylic acid, insufficient removal of carious tissue in the surrounding walls, contamination by saliva, and inadequate handling of the material. ${ }^{21,26}$ In this study, the children who did not cooperate to ensure adequate performance of the technique did not participate in the sample. The characteristics of lower height and lower mineral content of the primary tooth can also be pointed out as having less success using the ART technique, when there was involvement of multiple faces. ${ }^{23}$

ART has become established as a restorative alternative, based on several clinical trials, ${ }^{15,21,27,28}$ systematic reviews and meta-analyses. ${ }^{18,23,29}$ It is, therefore, a viable option to control dental caries in preschool children, in situations of social vulnerability, because it is a simple, relatively inexpensive implementation technique that can be performed in a school setting. In the sample used this study, a high prevalence of dental caries was observed, increasing with age, from a smaller rate among the two-year-olds, to a larger rate among the six-year-olds; furthermore, the disease was active in almost all the children. The presence of carious cavities demonstrates the children's lack of access to conventional dental treatment, associated with the diminished value of the primary teeth by guardians, based on their temporary nature, as well as the difficulty in controlling the child's behavior during dental care. ${ }^{30}$

The success of the ART technique is associated with the material being used; that is to say, this technique must be used with high-viscosity GIC to perform well. Vitro Molar ${ }^{\circledR}$ (DFL), sold in Brazil, has the advantage of being about $70 \%$ less expensive than Ketac Molar® (3M / ESPE). ${ }^{15}$ In this study, Ketac Molar ${ }^{\circledR}$ was found to have a better success rate than Vitro Molar ${ }^{\circledR}$ at 6 and 12 months, although the success rate of restorations by the latter was especially high at six months. Moreover, the surface micro-hardness of Vitro Molar ${ }^{\circledR}$ evaluated in vitro increased after as early as one week..$^{30}$ Low-cost GIC may interfere with standard GIC properties, and differ physically and mechanically from high-viscosity GIC. Both GIC alternatives are associated with water absorption and solubility, which can damage restorations and decrease the GIC success rate ${ }^{31}$.

Among the factors associated with the survival of the restorations, in both evaluation periods, the second molars had the highest success rates, as observed in another controlled clinical trial ${ }^{21}$. The size of the small to medium cavities was also associated with greater success of the restorations. Pacheco et al., ${ }^{21}$ however, did not observe differences in longevity and cavity size. The ART technique is ideally suited for small- to medium-depth lesions, preferably on a single face. ${ }^{10}$ In this study, a tendency of success was observed for small restorations (involving up to $1 / 3$ of the surface). Although systematic reviews and meta-analyse ${ }^{17,23,29}$ have shown that one-sided restorations on the occlusal surface of molars presented a higher survival rate, in the present study, there was no association between restoration survival and cavity type, whether Class I, II or III / V, corroborating other studies ${ }^{15,21}$.

This was the first study to test low-cost GIC performance by two dental surgeons trained and calibrated for the ART technique, unlike the study by Pacheco et al. ${ }^{21}$ which was performed by undergraduate students. Systematic reviews and meta-analyses only include studies by trained dental surgeons. ${ }^{23,29}$ Regarding the limitations of this study, one was that we were unable reevaluate at least $80 \%$ of the sample in one year's time; however, we came close, with $76.8 \%$. Several strategies have been developed to circumvent this problem, such as the selection of daycare centers located near elementary schools, so that children can be located after they leave the daycare center, as well as allowing three attempts for re-evaluation in case the child misses the scheduled day.

The results of this study indicate that highviscosity GIC has a greater survival rate than low-cost GIC. This factor should be taken into consideration when choosing the material to be used with ART. Although a lower cost GIC may be selected over high-viscosity GIC, all the costs associated with the entire treatment procedure must be borne in mind. If low-cost restorations fail more often, they must also be replaced more often than would be required if another material with 
better properties had been selected. Additional costs related to dentist fees and equipment wear should also be considered. Further studies should be conducted to assess whether using low-cost GIC would actually represent a significant savings to government programs. ${ }^{31}$

It should also be underscored that the success of the technique depends on its adequate indication for the procedure involved, as was the case of this study, regarding dentin caries lesions on one or two surfaces, with no painful symptomatology or evident pulp exposure. ${ }^{18}$ These results strengthen ART as a minimally invasive alternative with good resolution.
Hence, it should be viewed as the first choice of dentists, as a treatment to stop the progression of carious lesions in dentin, especially in children, because of its more patient-friendly approach. ${ }^{32}$

\section{Conclusion}

The success rate of restorations using low-cost GIC was especially high after six months. However, one year later, the restorations performed with high-viscosity GIC, in primary second molars with small or medium cavities, were more successful than those using low-cost GIC indicated for ART.

\section{References}

1. World Health Organization - WHO. The world health report: 2003: shaping the future. Geneva: World Health Organization; 2003.

2. Canadian Dental Association - CDA. Children wait too long for urgently needed dental care. Ottawa: Canadian Dental Association; 2010.

3. World Health Organization - WHO. World Health Statistics 2017: monitoring health for the SDGs. Geneva: World Health Organization; 2017.

4. Kassebaum NJ, Bernabé E, Dahiya M, Bhandari B, Murray CJ, Marcenes W. Global burden of untreated caries: a systematic review and metaregression. J Dent Res. 2015 May;94(5):650-8. https://doi.org/10.1177/0022034515573272

5. Petersen PE. World Health Organization global policy for improvement of oral health: World Health Assembly 2007. Int Dent J. 2008 Jun;58(3):115-21. https://doi.org/10.1111/j.1875-595X.2008.tb00185.x

6. Ministério da Saúde (BR). Secretaria de Atenção Básica. Pesquisa Nacional de Saúde Bucal: resultados principais. Brasília, DF: Ministério da Saúde; 2010.

7. Faustino-Silva DD, Figueiredo MC. Atraumatic restorative treatment-ART in early childhood caries in babies: 4 years of randomized clinical trial. Clin Oral Investig. 2019 Oct;23(10):3721-9. https://doi.org/10.1007/s00784-019-02800-8

8. Frencken JE, Holmgren CJ. How effective is ART in the management of dental caries? Community Dent Oral Epidemiol. 1999 Dec;27(6):423-30. https://doi.org/10.1111/j.1600-0528.1999.tb02043.x

9. Lima CV, Pierote JJ, Santana Neta HA, Lima MDM, Moura LFD, Moura MS. Caries, toothbrushing habits, and fluoride intake from toothpaste by Brazilian children according to socioeconomic status. Pediatr Dent. 2016;38(4):305-10.

10. Frencken JE, Makoni F, Sithole WD. Atraumatic restorative treatment and glass-ionomer sealants in a school oral health programme in Zimbabwe: evaluation after 1 year. Caries Res. 1996;30(6):428-33. https://doi.org/10.1159/000262355

11. Alves FB, Hesse D, Lenzi TL, Guglielmi CA, Reis A, Loguercio AD, et al. The bonding of glass ionomer cements to caries-affected primary tooth dentin. Pediatr Dent. 2013 Jul-Aug;35(4):320-4.

12. Mickenautsch S. How well are GIC product labels related to current systematic review evidence? Dent Update. 2011 Nov;39(9): 634-8,641-2,644. https://doi.org/10.12968/denu.2011.38.9.634

13. Freitas CN, Castelo PM, Sousa KG, Alonso GC, Fonseca F, Klein MI, et al. Educational strategies and atraumatic restorative treatment effect on salivary characteristics: a controlled clinical trial. Oral Dis. 2017 Nov;23(8):1116-26. https://doi.org/10.1111/odi.12706

14. Franca C, Colares V, Amerongen E. The operator as a factor of success in ART restorations. Braz J Oral Sci. 2011 Jan-Mar;10(1):60-4.

15. Olegário IC, Pacheco AL, Araújo MP, Ladewig NM, Bonifácio CC, Imparato JC, et al. Low-cost GICs reduce survival rate in occlusal ART restorations in primary molars after one year: A RCT. J Dent. 2017 Feb;57:45-50. https://doi.org/10.1016/i.jdent.2016.12.006

16. Menezes-Silva R, Cabral RN, Pascotto RC, Borges AF, Martins CC, Navarro MF, et al. Mechanical and optical properties of conventional restorative glass-ionomer cements - a systematic review. J Appl Oral Sci. 2019 Feb;27(0):e2018357. https://doi.org/10.1590/1678-7757-2018-0357

17. Raggio DP, Hesse D, Lenzi TL, Guglielmi CA, Braga MM. Is Atraumatic restorative treatment an option for restoring occlusoproximal caries lesions in primary teeth? A systematic review and meta-analysis. Int J Paediatr Dent. 2013 Nov;23(6):435-43. 
Does low-cost GIC have the same survival rate as high-viscosity GIC in atraumatic restorative treatments? A RCT

18. Tedesco TK, Calvo AF, Lenzi TL, Hesse D, Guglielmi CA, Camargo LB, et al. ART is an alternative for restoring occlusoproximal cavities in primary teeth - evidence from an updated systematic review and meta-analysis. Int J Paediatr Dent. 2017 May;27(3):201-9. https://doi.org/10.1111/ipd.12252

19. Dias AG, Magno MB, Delbem AC, Cunha RF, Maia LC, Pessan JP. Clinical performance of glass ionomer cement and composite resin in Class II restorations in primary teeth: A systematic review and meta-analysis. J Dent. 2018 Jun;73:1-13. https://doi.org/10.1016/i.jdent.2018.04.004

20. Ruengrungsom C, Palamara JE, Burrow MF. Comparison of ART and conventional techniques on clinical performance of glass-ionomer cement restorations in load bearing areas of permanent and primary dentitions: A systematic review. J Dent. 2018 Nov;78:1-21. https://doi.org/10.1016/i.jdent.2018.07.008

21. Pacheco ALB, Olegário IC, Bonifácio CC, Calvo AFB, Imparato JCP, Raggio DP. One year survival rate of ketac molar versus vitro molar for occlusoproximal ART restorations: a RCT. Braz Oral Res. 2017 Nov;31(0):e88. https://doi.org/10.1590/1807-3107bor-2017.vol31.0088

22. Hof MA, Frencken JE, van Palenstein Helderman WHP, Holmgren CJ. The atraumatic restorative treatment (ART) approach for managing dental caries: a meta-analysis. Int Dent J. 2006 Dec;56(6):345-51. https://doi.org/10.1111/j.1875-595X.2006.tb00339.x

23. Amorim RG, Leal SC, Frencken JE, Creugers NH, Frencken JE. Survival of atraumatic restorative treatment (ART) sealants and restorations: a meta-analysis. Clin Oral Investig. 2012 Apr;16(2):429-41. https://doi.org/10.1007/s00784-011-0513-3

24. Phantumvanit $P$, Songpaisan $Y$, Pilot T, Frencken JE. Atraumatic restorative treatment (ART): a three-year community field trial in Thailand: survival of one-surface restorations in the permanent dentition. J Public Health Dent. 1996;56(3 Spec No):141-5. https://doi.org/10.1111/j.1752-7325.1996.tb02424.x

25. Leal SL, Navarro MF, Frenken JE. Potencialização do tratamento restaurador atraumático. Pró-Odonto Prevenção. 2012;5(4):103-39.

26. Lo EC, Holmgren CJ. Provision of Atraumatic Restorative Treatment (ART) restorations to Chinese pre-school children: a 30-month evaluation. Int J Paediatr Dent. 2001 Jan;11(1):3-10. https://doi.org/10.1046/j.1365-263x.2001.00232.x

27. Arrow P. Restorative outcomes of a minimally invasive restorative approach based on atraumatic restorative treatment to manage early childhood caries: a randomised controlled trial. Caries Res. 2016;50(1):1-8. https://doi.org/10.1159/000442093

28. Amorim RG, Leal SC, Mulder J, Creugers NH, Frencken JE. Amalgam and ART restorations in children: a controlled clinical trial. Clin Oral Investig. 2014 Jan;18(1):117-24. https://doi.org/10.1007/s00784-013-0955-x

29. Nogueira LB, Martins GA, Moura LF, Lima MD, Moura MS. Clinical performance of atraumatic restorative treatment in children with severe early childhood caries. Rev Odonto Ciênc. 2013;28(2):36-40.

30. da Silva RC, Zuanon AC. Surface roughness of glass ionomer cements indicated for atraumatic restorative treatment (ART). Braz Dent J. 2006;17(2):106-9. https://doi.org/10.1590/S0103-64402006000200004

31. Calvo AF, Kicuti A, Tedesco TK, Braga MM, Raggio DP. Evaluation of the relationship between the cost and properties of glass ionomer cements indicated for atraumatic restorative treatment. Braz Oral Res. 2016;30(1):S1806-83242016000100201. https://doi.org/10.1590/1807-3107BOR-2016.vol30.0008

32. Frencken JE. Atraumatic restorative treatment and minimal intervention dentistry. Br Dent J. 2017 Aug;223(3):183-9. https://doi.org/10.1038/sj.bdj.2017.664 


\title{
Does low-cost GIC have the same survival rate as high-viscosity GIC in atraumatic restorative treatments? \\ A RCT. Braz Oral Res. 2019;33:e125.
}

\author{
Correct author's: \\ Where is read: \\ Marcoeli Silva de MOURA ${ }^{(a)}$ \\ Geovanna Peres de SOUSA ${ }^{(a)}$ \\ Maria Hellen Sâmia Fortes BRITO(a) \\ Mikaelle Claro Costa SILVA ${ }^{(a)}$ \\ Marina de Deus Moura de LIMA ${ }^{(a)}$ \\ Lúcia de Fátima Almeida de Deus MOURA ${ }^{(a)}$ \\ Cacilda Castelo Branco LIMA ${ }^{(a)}$ \\ It should read: \\ Marcoeli Silva de MOURA ${ }^{(a)}$ \\ Geovanna Peres de SOUSA ${ }^{(a)}$ \\ Maria Hellen Sâmia Fortes BRITO(a) \\ Mikaelle Claro Costa SILVA ${ }^{(a)}$ \\ Marina de Deus Moura de LIMA ${ }^{(a)}$ \\ Lúcia de Fátima Almeida de Deus MOURA ${ }^{(a)}$ \\ Renata Correa PASCOTTO(b) \\ Cacilda Castelo Branco LIMA ${ }^{(a)}$ \\ In pages 3, 5, 7 and 9 \\ Where is read: Moura MS, Sousa GP, Brito MHSF, Silva MCC, Lima \\ MDM, Lima CCB, et al. \\ It should read: Moura MS, Sousa GP, Brito MHSF, Silva MCC, Lima \\ MDM, Pascotto RC, et al.
}

